\title{
Evidencias microscópicas y moleculares de la presencia de fitoplasmas en plantas de murta (Ugni molinae Turcz.) afectadas por la enfermedad "escoba de bruja"
}

\author{
Nancy Andrade S. ${ }^{1}$, María Villagra H. ${ }^{1} \&$ Nolberto Arismendi S. ${ }^{2}$ \\ ${ }^{1}$ Instituto de Producción y Sanidad Vegetal, Facultad de Ciencias Agrarias, Universidad Austral de Chile, Isla Teja s/n, \\ Casilla 567, Valdivia, Chile; ${ }^{2}$ Escuela de Graduados, Facultad de Ciencias Agrarias, Universidad Austral de Chile, Isla Teja \\ s/n, Casilla 567, Valdivia, Chile
}

Autor para correspondencia: Nancy Andrade S., e-mail: nandrade@uach.cl

\begin{abstract}
RESUMEN
La murta o murtilla (Ugni molinae Turcz., Myrtaceae), es un arbusto frutal siempre verde, nativo de Chile. Su fruto es una baya globosa muy aromática y sabrosa, de gran potencial en consumo fresco e industrializado. El arbusto presenta en el follaje una enfermedad caracterizada por una incontrolable ramificación conocida como "escoba de bruja”, siendo la más común y destructiva, la cual podría estar relacionada con un agente biótico. Se realizaron cortes histológicos en tejidos con y sin síntomas de la enfermedad, los cuales se visualizaron mediante microscopía electrónica de transmisión. Se observó la presencia de microorganismos pleomórficos similares a fitoplasmas en los tejidos del floema en plantas enfermas. Pruebas moleculares mediante PCR permitieron confirmar la presencia de estos procariontes en tejidos enfermos, pero no en plantas asintomáticas, lo cual sugiere que estos microorganismos podrían estar asociados como agentes causales de la enfermedad escoba de bruja en murta. En futuros trabajos se espera obtener la identificación de este fitoplasma, sus vectores y dispersión en el sur de Chile.
\end{abstract}

Palabras clave: Myrtaceae, molicutes, diagnosis, TEM, PCR.

\section{ABSTRACT}

Microscopic and molecular evidence of phytoplasma in murta plants (Ugni molinae Turcz.) affected by witches'-broom disease

The murta or murtilla (Ugni molinae Turcz., Myrtaceae) is an evergreen shrub fruit native to Chile. Its fruit is an aromatic and tasty globose berry, great potential as a fresh product and for industrialized production. The most common and destructive disease of the foliage of this shrub is characterized by uncontrolled branching and known as "witches'-broom" disease; this could be related to a biotic agent. Histological cuts were made in tissues with and without symptoms of the disease, which were visualized by transmission electron microscopy. Pleomorphic microorganisms similar to phytoplasma in phloem tissue of diseased plants were seen. PCR molecular testing confirmed the presence of these prokaryotes in diseased tissues, but not in asymptomatic plants, suggesting that these microorganisms could be associated as causal agents of witches'-broom disease in murta. Future research is expected to identify this phytoplasma, its vectors and its dispersion in southern Chile.

Keywords: Myrtaceae, Mollicutes, diagnosis, TEM, PCR.

La murta (Ugni molinae Turcz., Myrtaceae), también conocida como murtilla, es una especie nativa de Chile. Es un arbusto frutal siempre verde, que se encuentra distribuido entre las regiones del Maule y Aysen, especialmente en la cordillera de la Costa y parte de la precordillera Andina (Seguel \& Torralbo, 2004). Su fruto es una baya globosa muy aromática y sabrosa, por lo cual presenta gran potencial productivo teniendo amplias posibilidades en el mercado interno y externo a través de productos con diferentes grados de industrialización. La industrialización de este arbusto frutal y el cultivo comercial, implica necesariamente, el desarrollo de programas de investigación dirigidos a determinar los factores que favorecen y afectan su producción. Esto último ha permitido observar que uno de los factores más destructivos y común, es la enfermedad denominada "escoba de bruja" (Figura 1A). La cual se caracteriza por una gran reducción en el tamaño de los brotes y en la proliferación excesiva de estos; las hojas se empequeñecen y aprietan adquiriendo una coloración rojiza a amarillenta, no permitiendo el desarrollo de frutos y cuando lo hacen presentan mal sabor. La aparición de esta enfermedad es discutible, pero los primeros reportes se hacen notar a inicio de los 80's. Novoa (1982), observa una sintomatología común y destructiva, que provoca "enanismo de brotes" o una formación de tipo de "escoba de bruja" en vástagos de murta y que según sus observaciones bajo microscopio, no encontró evidencias de insectos ni de hongos, por lo que supuso ser una infección viral. En 
realidad, esta sintomatología puede estar relacionada con varios factores bióticos o abióticos, pero comúnmente se la relaciona con infecciones producidas por fitoplasmas, los cuales han sido reportados en diferentes regiones del mundo, ejemplos de esto son los trabajos de Ghosh et al., 1999; Griffiths et al., 1999; Chapman et al., 2001; Montano et al., 2001; Barros et al., 2002; Khan et al., 2002; Marcone et al., 2004 , entre otros. Estos microorganismos son procariontes (clase Mollicute) intracelulares y restringidos al floema de las plantas, en donde han sido reportados en cientos de especies, muchas de ellas de importancia agronómica (Lee et al., 2000; Bertaccini, 2007). Los fitoplasmas son parásitos obligados que se desarrollan y reproducen asexualmente en el citoplasma de las células de sus hospederos (insectos y plantas) (Lee et al., 2000; Weintraub \& Beanland, 2006). Por esta condición, ha sido difícil su cultivo en condiciones in vitro, lo cual limita su caracterización o identificación (Lee et al., 2000). Una de las formas más comunes en determinar la presencia de fitoplasmas en los tejidos afectados es mediante la microscopía electrónica de transmisión (TEM), la cual permite observar en forma localizada la presencia de fitoplasmas, como también de partículas virales, ritcketsias y bacterias (Fránová et al., 2007). Por otra parte, las técnicas moleculares basadas en la reacción en cadena de polimerasa (PCR) con la utilización de partidores (iniciadores) universales y específicos para fitoplasmas, en función de los genes $16 \mathrm{~S}$ rRNA, región intergénica y 23S rRNA, que son ampliamente utilizados para la detección de estos procariontes (Smart et al., 1996; Heinrich et al., 2001). De acuerdo con estas herramientas, se planteó como objetivo determinar la presencia de fitoplasmas en plantas de murta afectadas por la enfermedad escoba de bruja.

Se recolectaron 30 ramillas de murta con y sin la presencia de síntomas de escoba de bruja (Figura 1A-B), en murtales que crecen en forma natural en los sectores de Los Notros de Curillanco, Arboretum Fundo Teja Norte y Estación Experimental Santa Rosa de la Universidad Austral de Chile, comuna de Valdivia (S 39 $49^{\prime}$; O 73 ${ }^{\circ} 14^{\prime}$ ), durante los años 1999 y 2000. Las preparaciones para observar en el microscopio electrónico de transmisión (TEM) (Hitachi, H700) se realizaron de acuerdo a la metodología adaptada de Bertaccini et al., (1999). Ramillas, pecíolos y hojas fueron cortadas en trozos de $\pm 1 \mathrm{~cm}$ de largo. Luego, estos trozos se introdujeron en un buffer fijador (buffer fosfato $0.05 \mathrm{M} \mathrm{a} \mathrm{pH}$ 7.0 y glutaraldehido al $2.5 \%$ ), los cuales se dejaron reposar por $\pm 15 \mathrm{~h}$ a temperatura ambiente $\left(20^{\circ} \mathrm{C}\right)$. Posteriormente, las muestras se lavaron (3 veces) en el mismo buffer fijador, seguido de un buffer post fijador (buffer fosfato $0,1 \mathrm{M} \mathrm{a} \mathrm{pH}$ 6.8 y tetraóxido de osmio al 2\%) por 4 h. Luego se repitió el lavado de las muestras ( 3 veces) con el mismo buffer. A continuación, las muestras se deshidrataron por diferentes grados de acetona (70, 90 y 100\%) por 10 min cada vez. Después, las muestras fueron sumergidas en resina plástica y seccionadas en cortes finos en ultramicrótomo automático (LKB, Nova). Finalmente, los cortes fueron teñidos con acetato de uranio por 20 min para ser observados a través del TEM, tomándose electromicrografias con distintos aumentos (4000X hasta 21000X).

La extracción de ADN geonómico de plantas y fitoplasmas fue basado en el protocolo de Lodhi et al. (1994), siendo adaptado para esta especie. Se utilizó $1.0 \mathrm{~g}$ de cada muestra (con y sin síntomas de escoba de bruja), las cuales fueron molidas en nitrógeno líquido y repartidas en cuatro tubos de $1.5 \mathrm{~mL}$, donde fueron disueltas en 600 $\mu \mathrm{L}$ (pre-calentado a $60^{\circ} \mathrm{C}$ ) de buffer de extracción CTABPVP 1\% (Tris-HCl $100 \mathrm{mM}, \mathrm{NaCl} 1.4 \mathrm{M}$, EDTA $20 \mathrm{mM}$ a $\mathrm{pH} 8.0,2 \%$ CTAB p/v; $0.2 \%$ 2-mercapetanol v/v y $1 \%$ polivinilpirrolidona PVP40-50G p/v) e incubado a $65^{\circ} \mathrm{C}$ por $30 \mathrm{~min}$. Se agregaron $600 \mu \mathrm{L}$ de cloroformo-octanol (24:1) frío $\left(-20^{\circ} \mathrm{C}\right)$ y se centrifugó a $6000 \mathrm{x}$ g por $5 \mathrm{~min}$. Se extrajo la fase superior y de nuevo se agregaron $400 \mu \mathrm{L}$ de cloroformo-octanol (24:1). Se repitió el centrifugado y otra vez se extrajo la fase superior. Después se agregaron acetato de amonio (7.5 M) a una concentración final de $2.5 \mathrm{M}$ y 380 $\mu \mathrm{L}$ de isopropanol frío. Todo se mezcló por inversión y se dejó precipitar toda una noche a $4^{\circ} \mathrm{C}$. Luego se centrifugó (13600 x g por $20 \mathrm{~min}$ ) y se lavó dos veces el precipitado de $\mathrm{ADN}$ con $500 \mu \mathrm{L}$ de etanol frío. A continuación, se volvió a centrifugar (13600 x g por $5 \mathrm{~min}$ ) y el precipitado formado se secó a temperatura ambiente (aprox. $30 \mathrm{~min}$ ). Finalmente, el ADN fue resuspendido en $100 \mu \mathrm{L}$ de buffer TE (Tris-HCl $10 \mathrm{mM}$ y EDTA $1 \mathrm{mM}$ a pH 8.0), además de ser cuantificado mediante un espectrofotómetro (Shimadzu, UV-120-12) y almacenado a $-20^{\circ} \mathrm{C}$ para su posterior utilización. Para determinar la presencia de ADN fitoplasmático se efectuó una primera reacción (PCR-directa) utilizando un par de partidores universales parafitoplasmas(P1/Tint)(Smartetal., 1996). A partir de esta reacción se realizó una PCR-anidada (nested-PCR) utilizando otro par de partidores (iniciadores) (Fu5/Ru3) (Lorenz et al., 1995). La PCR-directa se realizó en un volumen de $30 \mu \mathrm{L}$ por muestra, dividida en: $3.0 \mu \mathrm{L}$ de buffer PCR 10x, $1.0 \mu \mathrm{L}$ de $\mathrm{MgCl} 2(50 \mathrm{mM}), 2.5 \mu \mathrm{L}$ dNTP $(2 \mathrm{mM}), 0.5 \mu \mathrm{L}$ de cada partidor (P1/Tint) $(40 \mathrm{pmol} / \mu \mathrm{L}), 1.0$ taq ADN polimerasa $(1 \mathrm{U} / \mu \mathrm{L}), 20.5 \mu \mathrm{L}$ de agua destilada estéril y $1.0 \mu \mathrm{L}$ de ADN $(20 \mathrm{ng} / \mu \mathrm{L})$. Los parámetros de la PCR en el termociclador (MJ Research, PTC-150) consistieron de 30 ciclos con una desnaturalización de $94^{\circ} \mathrm{C}$ por 1 minuto ( 3 minutos para el primer ciclo), alineamiento a $56^{\circ} \mathrm{C}$ por 1 minuto y elongación a $72^{\circ} \mathrm{C}$ por 2 minutos (5 minutos para el último ciclo). Para la PCR-anidada se empleó el mismo volumen $(30 \mu \mathrm{L})$ y reactivos de la PCRdirecta por muestra, excepto quando se incluyeron $18.5 \mu \mathrm{L}$ de agua destilada estéril y $1.5 \mu \mathrm{L}$ de los partidores (Fu5/ Ru3) $(10 \mathrm{pmol} / \mu \mathrm{L})$ que amplifican una región de 900 pares de bases (pb) del gen 16S rRNA. La reacción de esta PCR fue de 30 ciclos a $94^{\circ} \mathrm{C}$ por 50 segundos $(3$ minutos para el primer ciclo), $55^{\circ} \mathrm{C}$ por $1: 25$ minutos y $72^{\circ} \mathrm{C}$ por $1: 50$ minutos (5 minutos para elongación final). Los productos de la reacción de la PCR-anidada se corrieron en geles de agarosa al $0.8 \%$ con $0.1 \mu \mathrm{L} / \mathrm{mL}$ de bromuro de etidio en buffer TBE $0.5 x$ (Tris $45 \mathrm{mM}$, ácido bórico $45 \mathrm{mM}$ y EDTA $1 \mathrm{mM}$ a pH 8.0) a 100 voltios por 40 minutos. Después 

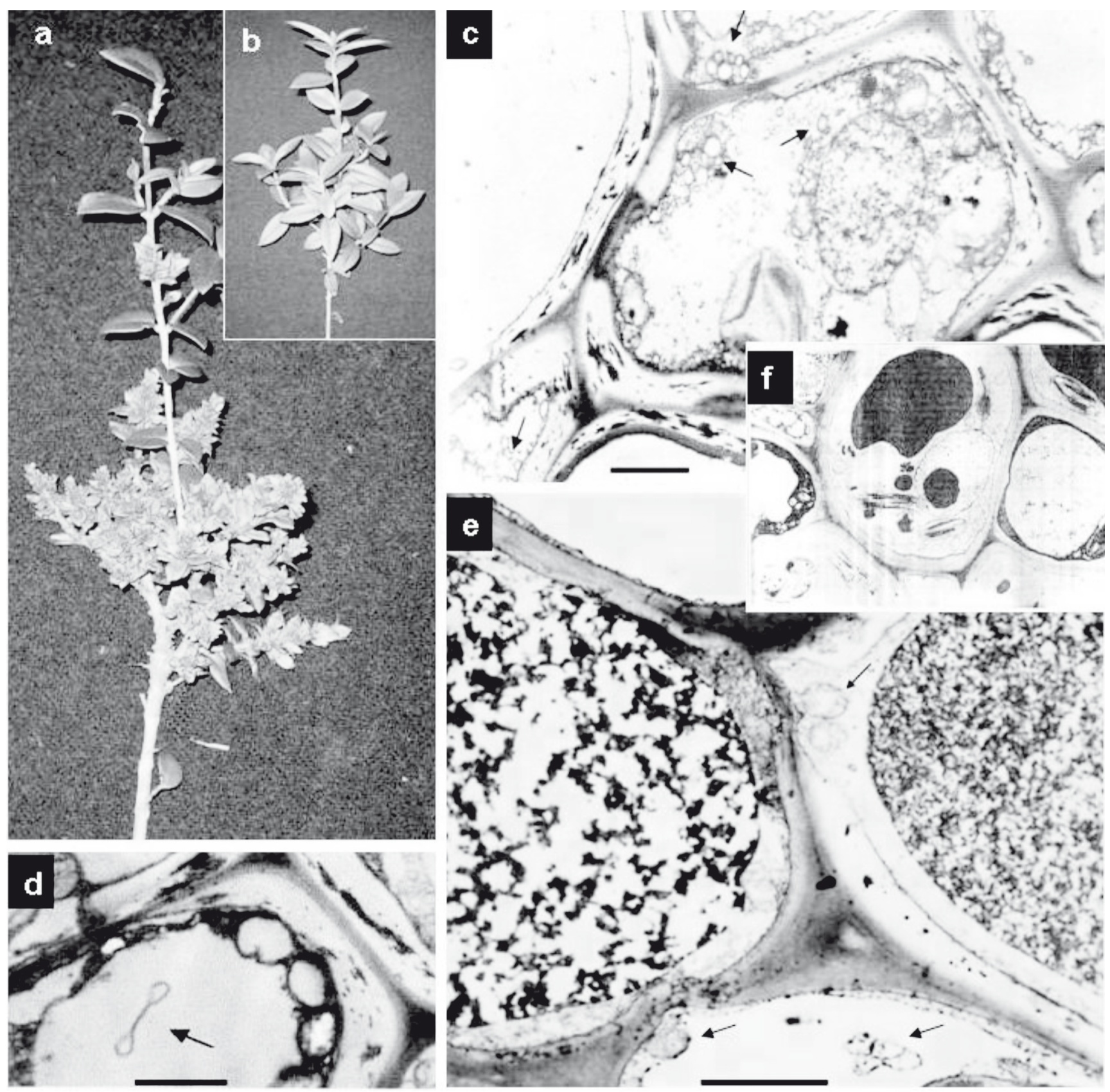

FIGURA 1 - Ramillas de murta con (a) y sin (b) síntomas de escoba de bruja y microscopía electrónica de transmisión (TEM) mostrando la presencia de cuerpos pleomórficos similares a fitoplasmas $(\rightarrow)$ en tejidos afectados $(\mathrm{c}, \mathrm{d}$, e) y sanos $(\mathrm{f})$. Barra $=1 \mu \mathrm{m}$.

los productos PCR fueron observados y fotografiados sobre un transiluminador de luz ultravioleta (Vilmer Lourmat, 6x 15W-312 nm). Además, para comparar los productos de PCR obtenidos provenientes del ADN de murta con presencia de escoba de bruja, se utilizaron productos de PCR de especies como: maíz (Zea mays), remolacha (Beta vulgaris var. saccharifera), frijol (Phaseolus vulgaris), papa (Solanum tuberosum) y crisantemo (Chrysanthemum sp.), que estaban contaminadas con fitoplasmas y que fueron amplificados por los partidores previamente mencionados.
En el caso de los cortes de plantas de murta con síntomas, se observaron microestructuras dentro de las células del floema, presentándose en forma irregular en esta región. Estos cuerpos microscópicos estaban limitados casi exclusivamente a los tubos cribosos, circundantes en su mayoría hacia la pared celular de estas células (Figura 1C), sin que se observaran estos elementos en células acompañantes o células parenquimáticas. Lo visto correspondía a cuerpos pleomórficos de un tamaño aproximado de 100 a $600 \mathrm{~nm}$ de diámetro, siendo las 
formas más frecuentes cuerpos esféricos u oblongos (Figura 1E). Estas microestructuras estaban rodeadas por un tipo de membrana rugosa y que ocasionalmente se encontraban con apéndices o constricciones, que podría ser principio de fisión binaria (Figura 1D-E), muy similar a lo observado en plantas afectadas por fitoplasmas (Chapman et al., 2001; Favali et al., 2004; Siddique, 2005). Sus formas, tamaños y contenidos, junto con la ubicación en las células degeneradas del floema de la planta enferma, son características similares a las descritas para fitoplasmas presentes en otras especies de plantas (Bertaccini et al., 1999; Kaminska et al., 1999; Fránová et al., 2003, Favali et al., 2004; Fránová, 2005; Siddique, 2005). En los tejidos control, plantas sin síntomas de escoba, no se observó la presencia de cuerpos pleomórficos de tipo fitoplasmático $\mathrm{u}$ otras estructuras similares (Figura 1F). De igual forma, en las células afectadas no se visualizó la presencia de partículas virales, hongos $\mathrm{u}$ otro tipo de procariontes (por ejemplo, espiroplasmas) que pudieran estar relacionados con la enfermedad. Por otra parte, la microscopía electrónica tiene la desventaja que cuando la concentración de fitoplasmas es baja, su eficiencia se reduce. Ésta técnica de comprobación visual de la existencia de fitoplasmas, debería ser complementada por técnicas moleculares para obtener un diagnóstico más acertado. En este sentido, el análisis de PCR (PCR-anidada) amplificó ADN utilizando partidores universales para fitoplasma en plantas de murta con síntomas de escoba bruja. Esto permitió la observación de bandas de ADN de aproximadamente $900 \mathrm{pb}$ de longitud, un tamaño similar para el ADN extraído de otras especies vegetales infectadas con fitoplasmas (maíz, remolacha, fríjol, papa y crisantemo), no habiendo amplificación de ADN fitoplasmático en plantas sanas (control) (Figura 2). El hecho que la PCR-anidada permitiera la detección de ADN fitoplasmático y no la PCR-directa, generalmente es atribuido a problemas de concentración de ADN y de inhibición de algunos polisacáridos y compuestos fenólicos (Green et al., 1999; Khan et al., 2004), lo que muchas veces, limita su visualización en geles de agarosa. Situación que es mejorada con una segunda reacción (PCR-anidada) que optimiza las condiciones e incrementa la sensibilidad (Khan et al., 2004). Sin embargo, es necesario mencionar que al menos un $40 \%$ de las muestras con síntomas evaluadas (30 ramillas) después de la segunda reacción, no amplificaron ADN fitoplasmático o dichas amplificaciones fueron inconsistentes, lo cual puede estar relacionado con la concentración irregular de ADN fitoplasmático o la presencia de procariontes contaminantes en los tejidos, como ha ocurrido en algunos casos reportados (Skrzeczkowski et al., 2001). En todo caso, estos resultados confirman las evaluaciones preliminares realizadas con microscopía electrónica de transmisión, indicando que la observación de cuerpos pleomórficos en tejidos con síntomas de escoba de bruja coincide con la presencia de fitoplasmas. Este es el primer reporte que asocia a estos procariontes como agentes causales de la enfermedad de escoba de bruja en plantas de murta, por lo que en futuros trabajos se espera que dicho diagnóstico sea confirmado con la identificación de este fitoplasma y los vectores relacionados a su infección y dispersión en el sur de Chile.

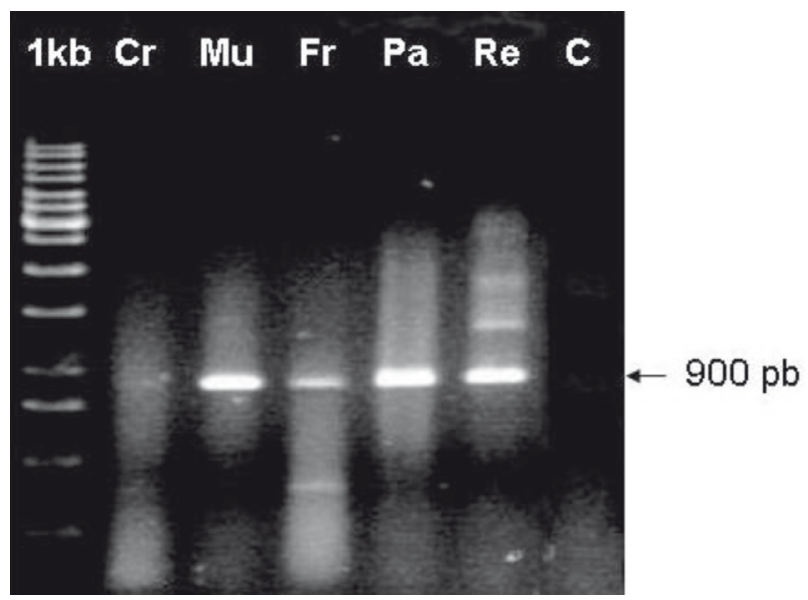

FIGURA 2 - Electroforesis en gel de agarosa (0,8\%) del ADN amplificado con los partidores universales para fitoplasmas, utilizando P1/Tint en primera reacción y fU5/rU3 en la segunda reacción (PCR-anidada). $1 \mathrm{~Kb}$ : Marcador de peso molecular, $\mathrm{Cr}$ : Crisantemo, Mu: Murta, Fr: Fríjol, Pa: Papa, Re: Remolacha, infectados con fitoplasmas. C: Control negativo.

\section{AGRADECIMENTOS}

Agradecemos a la Dirección de Investigación y Desarrollo (DID UACH S-98-23) de la Universidad Austral de Chile.

\section{REFERENCIAS BIBLIOGRÁFICAS}

Barros TS, Davis RE, Resende RO, Dally, EL (2002) Erigeron witches'-broom phytoplasma in Brazil represents new subgroup VII-B in 16S rRNA gene group VII, the Ash Yellows phytoplasma group. Plant Disease 86:1142-1148.

Bertaccini A (2007) Phytoplasmas: diversity, taxonomy, and epidemiology. Frontier in Bioscience 12:673-689.

Bertaccini A, Fránová J, Paltrinieri S, Martini M, Navrátil M, Lugaresi C, Nebesárová J, Simková M (1999) Leek proliferation: A new phytoplasma disease in the Czech Republic and Italy. European Journal of Plant Pathology 105:487-493.

Chapman GB, Buerkle EJ, Barrows EM, Davis RE, Dally EL (2001) A light and transmission electron microscope study of a black locust tree, Robinia pseudoacacia (Fabaceae), afected by witches'-broom, and classification of the associated phytoplasma. Journal of Phytopathology 149:589-597. 
Favali MA, Musetti R, Benvenuti S, Bianchi A, Pressacco L (2004) Catharanthus roseus L. plants and explants infected with phytoplasmas: alkaloid production and structural observations. Protoplasma 223:45-51.

Fránová J, Pribylová J, Simková M, Navrátil M, Válová P (2003) Electron microscopy and molecular characterization of phytoplasmas associated with strawflower yellows in the Czech Republic. European Journal of Plant Pathology 109:883-887.

Fránová J (2005) The Occurrence of phytoplasmas in apple trees showing branch twisting. Journal of Phytopathology 153:384388 .

Fránová, J, Petrzik K, Paprstein F, Kucerová J, Navrátil M, Válová P, Nebesárová J, Jakesová H (2007) Experiences with phytoplasma detection and identification by different methods. Bulletin of Insectology 60:247-248.

Ghosh D, Das A, Singh S, Singh S, Ahlawat Y (1999) Association of a phytoplasma with witches' broom, a new disease of acid lime (Citrus aurantifolia). Current Science 77:174-177.

Green MJ, Thompson DA, MacKenzie DJ (1999) Easy and efficient DNA extraction from woody plants for the detection of phytoplasma by polymerase chain reaction. Plant Disease 83:482-485.

Griffiths HM, Sinclair WA, Smart CD, Davis RE (1999) The phytoplasma associated with ash yellows and lilac witches'broom: 'Candidatus phytoplasma fraxini'. International Journal of Systematic Bacteriology 49:1605-1614.

Heinrich M, Botti S, Caprara L, Arthrofer W, Strommer S, Hanzer V, Katinger H, A. Bertaccini H, Da Camara ML (2001) Improved detection method for fruit tree phytoplasmas. Plant Molecular Biology Report 19:169-179.

Khan AJ, Botti S, Al-Subhi AM, Gundersen-Rindal DE, Bertaccini AF (2002) Molecular identification of a new phytoplasma associated with alfalfa witches'-broom in Oman. Phytopathology 92:1038-1047.

Khan J, Srivastava P, Singh K (2004) Efficacy of nested-PCR for the detection of phytoplasma causing spike disease of sandal. Current Science 86:1530-1533.

Kaminska M, Rudzinska-Langwald A, Korbin M (1999) Occurrence and identification of aster yellows related phytoplasma in Gladiolus in Poland. Acta Physiologie Plantarum 21:419-425.
Lee I-M, Davis RE, Gundersen-Rindal DE (2000) Phytoplasma: Phytopathogenic Mollicutes. Annual Review of Microbiology 54:221-255.

Lodhi ML, Ye G-N, Weeden NF, Reisch BI (1994) A simple and efficient method for DNA extraction from grapevine cultivars, Vitis species and Ampelopsis. Plant Molecular Biology Reporter 12:6-13.

Lorenz KH, Schneider B, Ahrens U, Seemüller E (1995) Detection of the apple proliferation and pear decline phytoplasma by PCR amplification of ribosomal and nonribosomal DNA. Phytopathology 85:771-776.

Marcone C, Gibb KS, Streten C, Schneider B (2004) 'Candidatus phytoplasma spartii', 'Candidatus phytoplasma rhamni' and 'Candidatus phytoplasma allocasuarinae', respectively associated with spartium witches'-broom, buckthorn witches'-broom and allocasuarina yellows diseases. International Journal of Systematic and Evolutionary Microbiology 54:1025-1029.

Montano HG, Davis RE, Dally EL, Hogenhout S, Pimentel JP, Brioso PS (2001) 'Candidatus phytoplasma brasiliense', a new phytoplasma taxon associated with hibiscus witches'-broom disease. International Journal of Systematic and Evolutionary Microbiology 51:1109-1118.

Novoa R (1982) Antecedentes sobre establecimiento y producción de frutos de la especie Ugni molinae Turcz. Tesis de Ingeniero Forestal. Universidad Austral de Chile. Valdivia.

Seguel I, Torralbo L (2004) Murtilla: El berry nativo del sur de Chile. Tierra Adentro No 57. pp. 20-25.

Smart CD, Schneider B, Blomquist CL, Guerra LJ, Harrison NA, Ahrens U, Lorenz KH, Seemuller E, Kirkpatrick BC (1996) Phytoplasma-specific PCR primers based on sequences of the 16S-23S rRNA spacer region. Applied and Environmental Microbiology 62:2988-2993.

Siddique AB (2005) Phytoplasma association with gerbera phyllody in Australia. Journal of Phytopathology 153:730-732.

Skrzeczkowski LJ, Howell WE, Eastwell KC, Cavileer TD (2001) Bacterial sequences interfering in detection of phytoplasma by PCR using primers derived from the ribosomal RNA operon. Acta Horticulturae 550:417-424.

Weintraub P, Beanland L (2006) Insect vectors of phytoplasmas. Annual Review of Entomology 51:91-111.

TPP 9023 - Recebido 11 Fevereiro 2009 - Acceptado 10 Agosto 2009 Editor de Sección: Mário Lúcio V. de Resende 